\title{
La epistemología se ocupa también de la ignorancia. Abordajes y enfoques teóricos en tensión*
}

\author{
Juan Alberto Fraiman
}

\section{Resumen}

En el presente trabajo nos ocuparemos de la ignorancia desde un tratamiento epistemológico. En primer lugar, las consideraciones de Karl Popper serán esclarecedoras para pensar en la ignorancia como principio activo del desarrollo del conocimiento y del progreso en la ciencia. Sin embargo, la perspectiva de Charles Mills y la teoría del reconocimiento de Axel Honneth introducirán otros aspectos relevantes acerca de la ignorancia, como su ligazón con el ejercicio del poder y la subordinación social, no tematizados lo suficiente por Popper. Por último, expondremos las tensiones e inquietudes que surgen de considerar estos diferentes abordajes sobre la Ignorancia.

Palabras clave: ignorancia, conocimiento, epistemología, reconocimiento, invisibilidad.

* En este texto encontramos uno de los intereses más grandes del autor: la epistemología. Esta se encuentran entre las últimas publicaciones del autor junto con la filosofía del lenguaje, pero en este texto, en especifico, encontramos una investigación sobre la ignorancia desde el punto de vista epistemológico.

Citar como: Fraiman, J. A. (2020). La epistemología se ocupa también de la ignorancia. Abordajes y enfoques teóricos en tensión. Cuadernos de Filosofía Latinoamericana, 41(122), 129-149.

Dol: https://doi.org/10.15332/25005375/5284

* Docente adjunto y coordinador responsable de la Cátedra de Epistemología en la Facultad de Ciencias de la Educación de la Universidad Nacional de Entre Ríos (UNER) y en la Facultad de Humanidades, Artes y Ciencias Sociales de la Universidad Autónoma de Entre Ríos (UADER). También es doctor en Ciencias Sociales (UNER) e investigador en teoría crítica. Correo electrónico: juanfraiman@hotmail.com 


\section{Epistemology Deals with Ignorance as Well. Theoretical Approaches and Perspectives in Tension}

\section{Abstract}

This paper deals with ignorance from an epistemological point of view. Firstly, Karl Popper's considerations sheds light on the understanding of ignorance as an active ingredient in the development of knowledge and the progress of science. However, the point of view of Charles Mills and Axel Honneth's theory of recognition, introduce other relevant aspects about ignorance- such as its connection with the exercise of power and social subordination- not sufficiently thematized by Popper. Finally, we will expound on the tensions and concerns that arise from considering these different approaches of ignorance.

Keywords: ignorance, knowledge, epistemology, recognition, invisibility.

\section{Introducción}

En ocasiones, la ignorancia y el error han sido reconocidos por la filosofía, como unos elementos centrales del propio desarrollo del conocimiento, no como su mera antítesis ${ }^{1}$. Incluso, aunque suene paradójico, la ignorancia ha jugado un rol crucial en el progreso de la ciencia, según algunas figuras emblemáticas del pensamiento epistemológico clásico y contemporáneo.

A su vez, estas consideraciones sobre el rol de la ignorancia y el error contienen una serie de consecuencias de índole práctica o, podríamos decir, de carácter moral y político, sumamente relevante e imposible de desconocer en una exposición de tales argumentaciones.

1 Es necesario reconocer que el presente trabajo surgió como producto de unas animadas discusiones e inquietudes compartidas con alumnos que asisten a las clases de Epistemología en el marco del programa "Educación en contextos de encierro" de la Facultad de Humanidades, Artes y Ciencias Sociales (UADER) en la Unidad Penal n 1 de Paraná, Entre Ríos, Argentina. 
Sin embargo, no siempre se ha argüido de la misma manera ni todas las miradas coinciden a la hora de subrayar la importancia del error y la ignorancia para el conocimiento y la ciencia. Existen diferentes valoraciones y perspectivas que se han ocupado de la ignorancia. Nos referimos, precisamente, a ciertos enfoques que podríamos situar - al menos provisoriamente - en el área de la sociología del conocimiento y otros que podríamos caracterizar como abordajes desde la filosofía de la ciencia, en un sentido más estrecho ${ }^{2}$.

En particular, nos interesa los aportes que pueden proporcionarnos, por un lado, el reconocido epistemólogo Karl Popper; y, por otro, el pensamiento del filósofo jamaiquino Charles W. Mills y la denominada teoría del reconocimiento de Axel Honneth. Este último caso, no es una propuesta elaborada con fines estrictamente gnoseológicos; se trata más bien de un enfoque teórico que tematiza las condiciones normativas del orden social contemporáneo e inscripta en la estela de la conocida teoría crítica de la Escuela de Fráncfort. No obstante, contiene algunas consideraciones de interés epistemológico que intentaremos recuperar con el propósito de enriquecer la reflexión acerca del conocimiento y la ignorancia.

En ese sentido, llevaremos a cabo el siguiente recorrido: en primer lugar, resaltaremos la importancia de la epistemología como disciplina reflexiva e interrogativa que se ocupa de la ignorancia. Para ello, resultarán esclarecedoras las apreciaciones que efectúa Karl Popper acerca de la ignorancia y el error en el progreso cognoscitivo y en el desarrollo de la ciencia. En segundo término, presentaremos la perspectiva de Charles Wade Mills acerca de la llamada “epistemología de la ignorancia”. En este caso, las disquisiciones sobre la ignorancia se ligan a diferentes prácticas sociales que juegan un rol fundamental en la reproducción de relaciones de dominio. Así, presentaremos un abordaje diferente que se extenderá y ahondará con Axel Honneth, en tercer lugar. El tratamiento de este último autor sobre la invisibilidad sentará las bases conceptuales, a nuestro entender, para una comprensión general de la ignorancia y del saber en términos de una fundamentación socio-normativa del conocimiento. Bajo esas premisas, nos aproximaremos a una reflexión de tipo filosófica mundana sobre la percepción y el acto cognitivo. De esa manera, estimaremos la contribución que puede hacer específicamente la teoría del reconocimiento en esta área temática, en consonancia con el planteamiento de Mills. Por último, emergerán algunos interrogantes e

2 Si bien tal delimitación no está exenta de dificultades y razonables cuestionamientos, la utilizaremos más adelante para caracterizar abordajes diferentes sobre la ignorancia. 
inquietudes con respecto a una posible "epistemología moral” esbozada por el propio Honneth, al confrontar el intento popperiano de fundamentar una teoría del conocimiento depurada de rastros psicosociales.

\section{La ignorancia: un componente imprescindible del conocimiento}

Normalmente, se entiende a la epistemología como el estudio y análisis del conocimiento científico en sus diferentes aspectos. Si bien no desconocemos las dificultades y controversias que existen acerca de su delimitación con respecto a otras disciplinas o denominaciones afines, tales como la teoría del conocimiento y la filosofía de la cien$\mathrm{cia}^{3}$, aquí pasaremos por alto tales cuestiones que desvían nuestro propósito inicial: mostrar la relevancia fundamental de la ignorancia para la comprensión filosófica del conocimiento y la ciencia.

No obstante, destacamos que la epistemología, a nuestro entender, no se limita a elaborar o reconstruir diferentes aspectos del conocimiento en general o de la ciencia en particular, sino que consiste principalmente en la capacidad de formular interrogantes que cuestionen o conmuevan aseveraciones y concepciones sobre el conocimiento habitualmente aceptadas. En ese sentido, la epistemología se presenta más bien como una actividad crítica y reflexiva. Incluso, podríamos admitir que las diferentes teorizaciones o propuestas epistemológicas sustantivas serían, en verdad, unas derivaciones o resultados de cierto ejercicio interrogativo-crítico previo y más fundamental. El análisis y la reconstrucción teórica constituyen, en definitiva, una respuesta tentativa a las dudas y preguntas anteriores ${ }^{4}$.

Tales interrogaciones y cuestionamientos apuntan, en esta ocasión, a la ignorancia. Efectivamente, se suele concebir a la ignorancia como una especie de brecha a subsanar para alcanzar el conocimiento. Entonces, el conocimiento sería lo opuesto a la ignorancia. Frente a determinado tipo de asunto o temática, a menudo se afirma que, o bien sabemos o permanecemos ignorantes; aun admitiendo cierta gradualidad — con

3 Por ejemplo, Klimovsky (1997, pp. 27-29) desarrolla algunos argumentos a favor de separar la filosofía de la ciencia de la epistemología y, a su vez, de la teoría del conocimiento; mientras que Pierre Thuillier (1975, pp. 13-21) se opone a tal delimitación.

4 De esa manera, por ejemplo, León Olivé ha subrayado el rol de la interrogación, la problematización y la reflexión para la epistemología como disciplina metacientífica (Olivé, 2000, pp. 25-43). 
respecto a cuánto sabemos y cuánto no-, no cambia la idea de fondo que conocer implica algo; así como sustraerse o quitarse la ignorancia de encima.

Otro tanto se dice, con frecuencia, del error o la equivocación: es aquello que se debe evitar cometer para adquirir cierto estado de conocimiento o sabiduría. Se puede estar en lo cierto o bien equivocado. Por lo tanto, el estar libre de errores sería una característica decisiva del conocimiento - en particular del conocimiento científico- de acuerdo a una visión convencional, aún no problematizada por la epistemología. Con todo, una determinada conceptualización de la ignorancia y del error pone en juego, al mismo tiempo, una caracterización del conocimiento y de la propia ciencia. De manera que ocuparse de la ignorancia no constituye un asunto menor.

Para ello, recurriremos en primer lugar a los aportes de Karl Popper, un destacado epistemólogo del siglo xx, quien ha puesto particular atención a estas cuestiones. Justamente, si partimos de que todo conocimiento $-\mathrm{y}$, en especial, el conocimiento científico- es conjetural e incierto (Popper, 2001, p. 2), la ignorancia y el error no son simples estados externos, ajenos y opuestos a él, sino auténticos principios activos de su desarrollo. El aumento del conocimiento no supone la eliminación o neutralización del error y la ignorancia. Sin equívocos, sin desajustes, sin contradicciones, sin preguntas y sin zonas hueras en el saber no hay intentos de solución, no hay impulso hacia otras elaboraciones teóricas. A su vez, cada novedad teórica abre el campo para nuevos problemas e interrogantes, y profundiza nuestra conciencia acerca de la inmensa ignorancia que nos rodea:

A cada paso que avanzamos y a cada problema que solucionamos, no solamente se nos descubre nuevos problemas pendientes de solución, sino que se nos impone la evidencia de que incluso allí donde creíamos estar sobre suelo firme y seguro todo es, en realidad, inseguro y vacilante. (Popper, 1973, p. 101)

Popper señala que los impresionantes avances de la ciencia durante los últimos siglos no nos conducen necesariamente a la plenitud del conocimiento certero, liberado de cualquier tipo de incertidumbre. Al contrario, se abandona el estado de seguridad y tranquilidad que brindan las aserciones y convicciones ya admitidas sin cuestionamientos. 
Así pues, la ignorancia forma parte de la ciencia y del conocimiento en una relación de tensión, pero también de necesaria complementación, ateniéndonos al esquema básico del falsacionismo de Popper. La producción de conocimiento parte de la formulación de interrogantes y del descubrimiento de determinados límites en los logros alcanzados al presente. Se formulan hipótesis audaces que luego serán sometidas a severos intentos de refutación. El hallazgo de contradicciones o errores significa un éxito para la ciencia, contra lo que corrientemente se piensa, pues obliga a descartar la teoría vigente y establecer una hipótesis completamente nueva e incompatible con la anterior, la cual solucione el problema planteado. El valor de una nueva visión de las cosas no es porque finalmente se conquiste una verdad inapelable, sino porque permite advertir cuán equivocado se encontraba antes, se gana con esto una mayor conciencia de la naturaleza provisoria y limitada del saber (Popper, 1980).

En definitiva, hay una cierta sabiduría que consiste en ser consciente de la vasta ignorancia que nos rodea y nos constituye como investigadores y seres cognoscentes. Ello se contrapone a la presunción de poseer un conocimiento indubitable que desdeña, minimiza, desconoce o reprocha cualquier signo de insuficiencia cognoscitiva (Popper, 1973, pp. 101-102).

Al mismo tiempo, tal sapiencia está conectada con una actitud ética específica que Popper denomina el principio de tolerancia (2001, p. 3). Si nos reconocemos como limitados en el alcance de nuestros saberes, abrimos la posibilidad de entablar un diálogo con otros que pueden someter a crítica nuestras afirmaciones y, por ese medio, aprender o progresar en nuestro conocimiento. El interlocutor es tan valioso como uno; por esto no se trata de un proceso de homogenización del otro a nuestra imagen. Por el contrario, cuanto más diferente es más significativo será su aporte ${ }^{5}$. Se establece un diálogo racional que implica admitir los propios límites y estar dispuesto a aprender del intercambio con los demás. Ello sucede necesariamente en un plano interpersonal que tiene como cometido lograr una aproximación a la verdad a través de la crítica recíproca (Popper, 2006).

5 Popper esgrime esta tesis en su polémica con Kuhn respecto al rol del marco general o común en las polémicas. En ese contexto, apela a la metáfora de la Torre de Babel para justificar el valor de las diferencias radicales en el debate y el ejercicio de la critica mutua: "No creo en la actual teoria de que para que una discusión sea fructifera, los que discuten tengan que tener mucho en común. Por el contrario, creo que cuanto más distinta sea su formación, más fructífera será la discusión. Ni siquiera hace falta empezar por tener una lengua común: si no hubiera existido la Torre de Babel hubiéramos tenido que construirla" (Popper, 1985, p. 46). 
En ese sentido, Popper reivindica la figura de Sócrates ${ }^{6}$, representada no solo en la celebérrima frase "solo sé que no sé nada", sino también en su actitud como interlocutor crítico que sitúa el diálogo como el lugar del aprendizaje y de la siempre ardua búsqueda de la verdad:

[...] la conciencia de las propias limitaciones, a la modestia intelectual de aquellos que saben con cuánta frecuencia yerran y hasta qué punto dependen de los demás aun para la posesión de este conocimiento, a la comprensión de que no debemos esperar demasiado de la razón, de que todo argumento raramente deja aclarado un problema, si bien es el único medio para aprender, no para ver claramente, pero sí para ver con mayor claridad que antes. (2006, p. 440)

He aquí el núcleo del racionalismo crítico popperiano. A partir de reconocerse como limitado en el saber, concibe a la racionalidad como una especie de actitud o disposición práctica de apertura hacia los argumentos críticos de los demás. Esto se opone a una concepción esencialista de la razón, podríamos decir, que la entiende como una especie de dotación intelectual susceptible de ser poseída o alcanzada por determinadas personas. Una especie de facultad que conduce inexorablemente hacia las cosas verdaderas; un instrumento infalible de acceso a la verdad.

Platón, a ojos de Popper, es un ejemplo emblemático de esa última concepción de la racionalidad que legitima una actitud autoritaria, elitista y solipsista, a la manera del Rey filósofo en La República. Desde esta posición no tiene sentido aprender de los demás, entablar un diálogo o escuchar las voces críticas. Los esfuerzos se dedicarían a captar, de manera solitaria - o, en todo caso, el acompañamiento ocuparía un rol secundario- aquello que es verdadero y, una vez alcanzado, hacer ver a los demás ese logro incuestionable; en otras palabras, imponérselo de alguna manera. En el fondo, se trata de una postura "seudorracionalista" que en lugar de promover el intercambio crítico de argumentos, legitima la imposición acrítica de opiniones ya acreditadas en el fuero íntimo (Popper, 2006, pp. 439-441).

Por lo demás, la perspectiva antiesencialista e interpersonal no se arroga una especie de autosuficiencia de la razón. El racionalismo crítico admite un origen de cierta

6 En verdad, Popper intenta reconstruir una tradición de pensamiento "falibilista", remontada al presocrático Jenófanes, y que prosigue con Nicolas de Cusa, Erasmo de Rotterdam y Voltaire en el mundo moderno (Popper, 1992). 
forma irracional. Siempre subyace una postura a favor de tal actitud racionalista que, en el fondo, es producto de una decisión no racional. Al respecto, Popper habla de una "fe irracional en la razón" (2006, p. 444). Si nos encontramos inmersos en el cruce de argumentaciones polémicas con otros, esto ya supone haber tomado partido por la actitud racional y haber renunciado a imponer coactivamente nuestro punto de vista a los demás. Esta insoslayable condición irracional, según Popper, nos muestra que la racionalidad, en un sentido más auténtico, está siempre cercada y derivada de componentes no racionales y, además, nos obliga a presumir un espacio de libertad en el cual se adopta una posición a favor o en contra de tal postura. Dicha elección es una cuestión intrínsecamente moral (Popper, 2006, p. 445). Expresado de manera sumaria, podríamos aseverar que una concepción de la ignorancia y del error como principios activos en el desarrollo del conocimiento implica, a la vez, una predisposición de índole práctico-moral; no es un asunto puramente teórico-cognitivo.

Por último, agregamos que el principio de falibilidad de la razón adquiere un inequívoco significado político, ligado a lo que Popper denomina el anti-autoritarismo. Esto es, el principio de la ignorancia prohíbe sistemáticamente encumbrar cualquier tipo de autoridad - aun en nombre de la razón y el saber experto de los científicos- que exija la obediencia ciega. En todo caso, el reconocimiento de la falibilidad cognoscente conduce a pensar un tipo de organización social conformada por instituciones "abiertas" que respeten la libertad de los individuos y que evite, por sobre todas las cosas, la erección de un poder coercitivo desmesurado en base a ciertas atribuciones de infalibilidad teórica, práctica y técnica (2006, pp. 454-470).

\section{La epistemología de la ignorancia en las prácticas sociales: la perspectiva de Charles Made Mils}

El filósofo jamaiquino Charles Wade Mills (1997), en su libro The Racial Contract, acuña o hace suya la expresión "epistemología de la ignorancia”, otorgándole una significación específica. A grandes rasgos, tal denominación alude a un programa de investigación acerca de las diferentes formas de ignorancia y intenta esclarecer cómo se producen y sostienen, con qué tipo de prácticas sociales están vinculadas, y qué papel juegan en ellas. Así, se analiza el rol del poder en la producción de conocimiento y en las visiones globales del mundo (Shannon y Tuana, 2007, pp. 3-4). 
Aquí también se niega que la ignorancia consista en un espacio vacío dado de manera accidental o causal. En realidad, la ignorancia se produce de manera activa y sistemática, con fines de explotación y dominación. Particularmente, Mills se ocupa de indagar el fenómeno del racismo y la supremacía blanca en América (Mills, 2007).

En ocasiones, se ha señalado que la epistemología de la ignorancia consiste también de una epistemología invertida (Shannon y Tuana, 2007, p. 2), ya que presta particular atención a las disfunciones cognitivas en articulación con prácticas y patrones de configuración cultural. En ese sentido, se analiza cómo el hombre blanco tiende a no entender el mundo segregacionista en el que vive $y$, de esa manera, toma beneficios de sus jerarquías y privilegios sociales. Allí se abre un abanico de innumerables aspectos socioculturales a indagar: el olvido histórico de los logros de la gente de color y de las atrocidades cometidas por los blancos, el franco desconocimiento de los pueblos originarios, de los rasgos étnicos y lingüísticos propios de los afrodescendientes en América, del papel de los asiáticos en la economía norteamericana, de la experiencia de empobrecimiento de las clases desposeídas, de padecimiento en la subordinación de género, etc. (Mills, 1997).

Sin embargo, no se trata únicamente de ignorar determinados rasgos nucleares de la vida social y de la historia humana, sino de producir y organizar estructuras cognoscitivas específicas, ancladas en particulares relaciones de poder. Se reproducen y consolidan esquemas de interpretación que asocian, por ejemplo, a los blancos con la civilización, mientras que los negros encarnan la existencia silvestre y salvaje, representando por contraste el ánimo perezoso y negligente, frente al espíritu emprendedor atribuido comúnmente a los pueblos europeos (Mills, 2007, p. 17).

La epistemología de la ignorancia constituye además una crítica a los supuestos individualistas y solipsistas del conocimiento y la reflexión en el modelo filosófico cartesiano que niega o no ha advertido suficientemente la estructuración grupal de la producción de conocimiento (Mills, 2007, p. 15).

En efecto, normalmente se aparta lo puramente cognitivo de lo sociológico. Aun cuando se reconocen los aspectos sociales y el carácter de "agente" del sujeto cognoscente, el problema étnico-racial no emergía como un componente sistemáticoestructural. Incluso, cuando se involucra lo social en el conocimiento, puede subyacer 
una representación de lo social en donde lo racial o la subordinación de género se constituyen como anomalías o excepciones que no presentan ningún valor estructural (Mills, 2007, pp. 16-17).

En lugar de enfocarse en los individuos, la epistemología de la ignorancia se concentra en la distribución social, por así decirlo, del conocimiento y del error. Entonces, considera que el error, las falsas creencias y la equivocación son fenómenos no accidentales ni derivados de la naturaleza humana equívoca o sesgada, sino que están ligados a mecanismos sociales de interacción. La ignorancia reproduce patrones de comportamiento social y vínculos de poder.

Por lo tanto, a diferencia de Popper, las consideraciones acerca de la ignorancia y el error no se infieren aquí de una concepción falible o conjetural del conocimiento, sino de su ligazón sistemática y su funcionalidad en una estructura social de dominio. Podríamos aseverar, por el momento, que el abordaje específico de Charles Wade Mills acerca de la ignorancia y del error parece más bien seguirse de una sociología del conocimiento.

Si bien Popper no desconoce el vínculo entre la vida social y el desarrollo del conocimiento e incluso enfatiza el carácter social e interpersonal de la racionalidad crítica (Popper, 2006, p. 439), se esfuerza por fundamentar la delimitación entre los aspectos históricos, sociales y psicológicos que considera parte del contexto de descubrimiento, y los componentes específicamente teórico-metodológicos del conocimiento, propios del contexto de justificación o validación (Popper, 1980, pp. 30-32), retomando el inconfundible lenguaje que adoptó la filosofía analítica a comienzos del siglo xx. Bajo esos parámetros, no registra ninguna conexión determinante entre aquellos elementos sociogenéticos y las estructuras lógico-teóricas.

Más aún, para Popper sería necesario mantener esta distinción que evite perder de vista la reflexión acerca del conocimiento en sí mismo, más allá de sus condicionamientos mundanos. La confusión entre ambos contextos puede dejar en pie determinados supuestos sin problematizar, como la presunción de la verdad manifiesta. Con esto, si reducimos los motivos de la ignorancia a cuestiones sociales, se corre el riesgo de suponer erróneamente que, liberados de tales cuestionamientos y ataduras, la verdad se manifiesta de forma inmediata e inequívoca. Extremando tal versión, daría lugar a una teoría conspirativa de la verdad (Popper, 1992, pp. 26-29). 
Desde luego que Mills podría responder a tal objeción afirmando que no intenta contraponer la ignorancia al saber de la verdad; no admitiría que, sorteados los obstáculos sociales, las cosas se manifiestan puras y cristalinas, tal como son. Frente a la ignorancia del opresor, Mills no opone la verdad revelada, sino la ignorancia de la resistencia que se propone desaprender lo aprendido justamente en tales condiciones de subyugación normalizada y, en principio, aceptada sin reparos (Shannon y Tuana, 2007, p. 2).

En esta somera comparación, se podría aún añadir otra diferencia crucial que distingue el enfoque de Popper con respecto a Mills. En concreto, Popper utiliza el caso del desarrollo científico y de las prácticas de la ciencia experimental como ejemplos para pensar la tensión entre el conocimiento y la ignorancia. Si bien no lo concibe como algo que sucede de manera exclusiva o solo privativa de la ciencia, es allí donde se expresa de una manera más plena. En cambio, Mills hace referencia permanente al tipo de saber cotidiano o mundano, que rige hábitos y configura relaciones sociales en un sentido más amplio que las actividades y procedimientos reglados del ámbito científico. Esos saberes abarcan y se nutren de esferas sociales que exceden los espacios de formación académica y acaban por impregnar la totalidad de las actividades humanas, aun en aquellos lugares de experticia tecnocrática aparentemente más distantes de la cotidianeidad.

De todas formas, estos aspectos más controversiales se retomarán en las conclusiones, una vez expuesta la perspectiva de Honneth; pues allí se acentuarán, a nuestro criterio, las tensiones entre los aspectos cognoscitivos, la perspectiva científica y los condicionamientos sociales en torno a la ignorancia.

\section{Una presentación a la teoría del reconocimiento de Axel Honneth}

Axel Honneth se ha constituido en el heredero más reconocido, en la actualidad, de la denominada teoría crítica de la Escuela de Fráncfort ( Hernández y Herzog, 2011), principalmente a través de la elaboración de su teoría del reconocimiento ${ }^{7}$. En ella, el autor se propone reconstruir los principios normativo-sociales que rigen la dinámica

7 Su teoria del reconocimiento ha sido presentada en su publicación La lucha por el reconocimiento. Por una gramática moral de los conflictos sociales (Honneth, 1997) en el año 1992 y contiene desarrollos posteriores publicados como artículos sueltos, entrevistas, libros, compendios, etc. En los últimos años, 
del desarrollo histórico y estructuran la sociedad capitalista actual. Su filosofía social pretende recuperar algunos aspectos cruciales del programa inicial de la Escuela de Fráncfort, postulado por Max Horkheimer en su papel de director en los años treinta del siglo xx, en cuanto al carácter interdisciplinario y el impulso crítico-emancipador que a su criterio ha perdido fuerza posteriormente. En su opinión, el desarrollo ulterior, en las principales figuras de Adorno y Horkheimer, fue virando hacia un tipo de análisis excesivamente especulativo y aporético. La Teoría de la acción comunicativa dada a conocer de manera más sistemática y completa a comienzos de los ochenta por su maestro, el renombrado pensador alemán Jürgen Habermas, tampoco pudo subsanar los problemas de fundamentación normativa y los déficits sociológicoempíricos que acusan, en su parecer, las disquisiciones teóricas de los francforteses durante el siglo $\mathrm{xx}^{8}$.

En términos generales, la cuestión del reconocimiento ocupa un papel central en la perspectiva de Honneth. En vista a ello, destacaremos algunas derivaciones que consideramos significativas para nuestro propósito. Por un lado, todo individuo y grupo social se encuentra siempre inserto en una relación de reconocimiento que va a ser fundamental en su propio despliegue y conformación. El reconocimiento significa, en términos elementales, el acto mismo de aceptar al otro, valorándolo positivamente, y constituye un presupuesto ineludible de cada interacción. En cualquier vínculo humano, se antepone una aceptación o rechazo del otro en términos pre-cognitivos, por así decirlo; aunque no consiste en un mero acto emotivo, ya que comporta también determinados criterios morales no completamente arbitrarios (Honneth, 2007, pp. 90-113).

Así pues, el concepto de reconocimiento supone una interdependencia y reciprocidad insoslayable. El desarrollo de cada individualidad en su singularidad y la ampliación en los márgenes de libertad y autonomía dependen del grado de reconocimiento o menosprecio puesto socialmente en juego. El reconocimiento actúa como una fuerza que regula y conforma el tipo de relación social establecida de manera mutua, afectando a la par las dos caras del vínculo. De ello nadie puede sustraerse; está presente, por ejemplo, en el trato que el señor de la casa proporciona a la trabajadora doméstica; en el

se ha ocupado del desarrollo de una teoría de la Justicia en base a la filosofía del derecho de Hegel, aunque está naturalmente conectado con su teoría del reconocimiento (Honneth, 2014).

8 Tales lecturas críticas acerca del devenir de la Escuela de Fráncfort ya las había expuesto Honneth (2009) en su obra más temprana, titulada Crítica del Poder. Fases en la reflexión de una Teoría Crítica de la sociedad, que constituye una versión ampliada de su tesis doctoral. 
porte del hombre de negocios y en el modesto empleado en una obra de construcción; en la investidura de una magistratura consagrada y en el pordiosero completamente marginal al ejercicio efectivo de la ciudadanía, etc. (Honneth, 1997, pp. 206-215).

Asimismo, Honneth intenta apartarse de aquellas posturas denominadas multiculturalistas y comunitaristas (aunque sin negar importantes puntos en común) que también utilizan la noción de reconocimiento, pero subrayan unilateralmente, a su juicio, el problema de la constitución de la identidad abocada a realzar las diferencias entre grupos culturales, dejando en un segundo plano las cuestiones relacionadas con las desigualdades económicas y el problema de la explotación en el trabajo (Honneth, 2010).

Convendría mejor la expresión hegeliana "lucha por el reconocimiento" para referir la postura de Honneth. Las relaciones de reconocimiento recíproco son siempre frágiles, precarias y parciales (en cuanto a la valoración positiva del prójimo y de sí mismo), contienen sentimientos de insatisfacción, demandas de mayor reconocimiento, rechazos, etc. Las exigencias empujan a luchar por un mayor y mejor reconocimiento que no puede describirse exclusivamente como una relación de fuerza entre pares o grupos de pares, sino también como la búsqueda de la "aceptación" del otro en una escala de criterios renovada que reconfigura completamente la propia relación social. Así, por ejemplo, se puede inteligir que el proletariado no solo batalla por mejorar sus condiciones de vida a expensas de quienes detentan los medios de producción, sino también por ser admitidos en toda su dignidad y valía social; este tipo de reconocimiento, podríamos decir, de orden superior (pues no se trata simplemente de recompensar mejor a una persona por su trabajo, sino de tratarlo como un igual y a la par apreciar su singularidad irreductible), requiere una mudanza de carácter cualitativo en el tipo de enlace social y en la conformación de las subjetividades en juego (Honneth, 1997, pp. 193-205).

Inspirado particularmente por los escritos de Hegel en su período de Jena, la lucha por el reconocimiento proporcionará un sugestivo esquema de interpretación de las transformaciones históricas y los modos de reproducción social: el quiebre de una unidad originaria genera una pugna entre partes que solo se puede resolver en el establecimiento de un nuevo tipo de relación superior, de manera que el conflicto mismo constituye el motor de dicho cambio. Las partes mismas ingresan en ese enfrentamiento bajo motivaciones morales y psíquicas, ganando conciencia acerca del 
carácter dependiente que significará el logro de sus pretensiones: un aumento en los márgenes de libertad y una mayor autonomía. La autorrealización y la emancipación individual no requieren un desprendimiento de los demás sino la conformación de un nuevo tipo de interdependencia social (Honneth, 1997, pp. 15-81).

Honneth identifica tres patrones de reconocimientos que establecen las condiciones de interacción posible en las sociedades contemporáneas: el amor, el derecho y la solidaridad. En ese orden, configuran niveles de reconocimientos escalonados que se van desplegando, cada uno de ellos incorpora al anterior, pero lo supera, ya que implica un nivel más exigente de valoración social. Se podría decir que se trata de un desarrollo dialéctico encarnado en formatos institucionales diferenciados - respectivamente son la familia, el Estado y el mercado- y conformando la sociedad capitalista actual en sus diversas dimensiones. Pero no se reduce a establecer formas claras y fijas de organización social; en ellas mismas conviven procesos contradictorios impulsados por experiencias disonantes que van reformulando sus estructuras y tensando sus límites hacia formas de reconocimientos más elevadas (Honneth, 1997, pp. 114-159).

Con su teoría del reconocimiento, Honneth aspira a reconstituir una presunta escisión, en el análisis social, entre los aspectos materiales (en términos de un marxismo convencional, referido a la infraestructura económica) y el nivel simbólico-cultural. Entonces, no se trata simplemente de dar cuenta de los conflictos en las aspiraciones a la identidad singularizada, sino de buscar unos principios que expliquen la dinámica conflictiva de la reproducción social en términos globales, incorporando a la vez las pugnas por la distribución económica y los derechos culturales en la constitución identitaria de los individuos y los grupos sociales. Al mismo tiempo, no se trata de propugnar una lógica de enfrentamientos en términos utilitarios y de mera imposición del dominio; la lucha por el reconocimiento supone más bien, en el lenguaje estricto de Honneth, un acontecimiento moral y un evento social (Honneth, 2010, pp. 42-43).

Igualmente, no se puede concebir la "lucha" sin apelar a un determinado tipo de experiencias subjetivas de carácter negativo que Honneth describe como el eje del despliegue de las relaciones de reconocimiento. Esto es, la negación del reconocimiento, entendida globalmente como desprecio o menosprecio, ocupa un lugar fundamental no solo porque permite entender el daño a la integridad psíquica como patología social, sino también porque se sitúa allí la presión subjetiva y la motivación moral para luchar y superar el padecimiento (Honneth, 1997, pp. 160-169). 
Además, en las experiencias de menosprecio podemos ver con claridad cómo actúan las expectativas en un movimiento dialéctico que va elevando la pretensión de reconocimiento a través del impulso negativo. $\mathrm{O}$ sea, tiene sentido la lesión psíquico-moral en tanto debemos suponer que los individuos o grupos sociales esperan ser reconocidos y entonces esas anticipaciones son desmentidas. Ahora bien, esas proyecciones se forjaron en vivencias anteriores de reconocimiento positivo y abren las puertas para aspirar a postreras relaciones de reconocimiento aún más exigentes.

\section{La invisibilidad como fenómeno social desde la teoría del reconocimiento}

Desde la teoría del reconocimiento, presentaremos a la invisibilidad como un acontecimiento social específico e intentaremos tejer algunas posibles articulaciones con la epistemología de la ignorancia de Mills.

En primer lugar, la invisibilidad se constituye en un caso característico de reconocimiento denegado. Honneth toma como punto de partida de su reflexión, la novela del escritor Ralph Ellison, El hombre invisible, que narra justamente el proceso de invisibilización padecido por su protagonista, un hombre negro inmerso en la sociedad norteamericana de mediados del siglo xx (Honneth, 2011).

La invisibilidad reúne todas las características que hacen al desprecio: en una situación específica, se actúa frente a una persona fingiendo desconocerla, como si ella misma no existiera, ignorándola abiertamente. Naturalmente, la invisibilidad no tiene que ver con la desaparición física de una persona, sino con una falta de reconocimiento mínimo que adquiere un carácter público-social. El hecho de desconocer intencionalmente a alguien presente en el mismo espacio físico requiere del uso de determinados gestos simbólico-expresivos para indicar a todos los demás la insignificancia social de aquel ser devenido invisible. La persona afectada percibe de modo inequívoco la afrenta y lo experimenta como tal. A su vez, demanda de cualquier manera una visibilidad, como en el caso del personaje principal de El hombre invisible de Ellison, el cual se enoja, golpea, intenta agredir, etc. Desde el punto de vista de la teoría del reconocimiento, se contrarían expectativas forjadas en experiencias primarias de reconocimiento, preparando el terreno para la lucha recognoscitiva, en tanto la existencia como tal y su valía como ser social y moral están comprometidos en esa valoración intersubjetiva (Honneth, 2011, pp. 166-169). 
Como en cualquier caso de negación del reconocimiento, la invisibilidad revela un trasfondo sociohistórico específico de dominación. Podemos esbozar un sinnúmero de casos que se entretejen en configuraciones epocales diversas: los nobles actuando frente a la servidumbre, el señor de la casa que no saluda a su empleada doméstica, la manera en cómo una figura jerárquica se dirige a un subordinado en una institución militar, educativa o eclesiástica, etc. Tales apreciaciones se pueden conectar con el enfoque de Mills acerca de la epistemología de la ignorancia: la invisibilidad constituye un tipo de ignorancia deliberada; se transforma en una forma social de sutil humillación y funciona como un acto simbólico-expresivo que consolida o refuerza patrones de sujeción social. De esa manera, la selectividad del saber y la praxis adosada a ella cumplen un rol relevante en el ejercicio del poder.

Ahora bien, si proseguimos el planteo de Honneth, notaremos que la comprensión analítica del acto de la invisibilidad requiere algunas delimitaciones conceptuales añadidas, que involucran nuestra noción corriente de conocimiento e ignorancia.

En primer lugar, es necesario deslindar el significado del término conocer, en tanto identificar a alguien o algo como un individuo específico a través de la observación de sus características particulares, del "re-conocer" como un acto expresivo, mediante el cual se efectúan intencionalmente ciertas apreciaciones valorativas acerca de un individuo, necesariamente de carácter público, pero con claras consecuencias en su autopercepción. Como recalcábamos anteriormente, reconocer significa juzgar de manera positiva y constituye en sí mismo una acción que posee efectos en el otro, en su constitución psíquico-social y, nada menos, en su autoapreciación moral. El reconocimiento posee en esencia un componente inescindible de carácter performativo, mientras que el mero hecho de observar - en tanto aplicar los sentidos hacia un objeto determinado para extraer de allí cierta descripción identificante - no guarda, en primera instancia, ninguna consecuencia performativa ni moral: el sujeto cognoscente capta algo fuera de sí, el objeto ya constituido, sin ningún otro tipo de vínculo ni efecto que emane de esa misma situación cognoscitiva (Honneth, 2011, pp. 169-174).

La invisibilidad como caso emblemático de ignorancia social activa, conserva como contraparte ya no solo el conocimiento llano, sino el proceso de reconocimiento en todas sus dimensiones socio-normativas. La ignorancia, en ese sentido, implica la supresión de aquellos aspectos que se despliegan en el acto mismo de reconocer y reconocerse a sí mismo. 
Honneth acentúa el carácter expresivo del acto recognoscitivo en tanto excede la utilización del lenguaje y se refiere principalmente a los recursos prelingüísticos, tales como expresiones faciales, gestos, movimientos y posiciones corporales adquiridos e internalizados desde las más tempranas experiencias interactivas, que regulan las manifestaciones recíprocas de afecto (2011, p. 171). Un inmenso acervo de exteriorizaciones no lingüísticas que no desaparecen en la vida adulta, más bien se estilizan sin dejar de tener una importancia central en la conformación de los vínculos intersubjetivos ${ }^{9}$.

Estos elementos expresivos, configurados culturalmente, conforman siempre una amplia gama de variaciones y matices y resultan efectivos en cualquier escenario cotidiano. Es así para la apreciación positiva del reconocimiento como para su denegación: pues, entonces, la invisibilidad se construirá mediante una puesta en escena de un complejo y sutil espectro de señales e indicaciones, en su mayoría de carácter no lingüístico, pero no por ello menos determinantes y categóricas a la hora de cometer el acto lesivo ${ }^{10}$.

Por otra parte, si nos atenemos a las consideraciones previas en torno al reconocimiento, la invisibilidad y el conocer, conviene revisar también lo que entendemos por "percepción". Para Honneth, el acto mismo de reconocer significa ya percibir, pero ello supone, por así decirlo, algo más que simplemente ver. Se trata de un acto expresivo y valorativo que contiene una actitud aprobatoria hacia los demás y cubre fundamentalmente el apreciar al otro en su dignidad, en su valía incondicional (2011, pp. 179-180).

Entonces, ya no resulta suficiente con establecer aquella primera distinción entre conocer y reconocer. Honneth concluye que el reconocimiento precede al conocimiento, dado el carácter intrínsecamente evaluativo que presenta cualquier percepción, vinculado a los procesos de socialización más tempranos, a la configuración de una

9 Honneth recurre a las investigaciones del psiquiatra estadounidense Daniel Stern, abocado al estudio empírico de las interacciones en la lactancia y a su relevancia en el posterior comportamiento adulto: "[...] los rituales de saludo de las personas adultas, que permiten reconocer, mediante expresiones faciales delicadamente matizadas, en qué relación social particular se encuentran mutuamente" (Honneth, 2011, p. 171).

10 No es difícil ejemplificar aqui para nuestra cultura cómo a cada menudo gesto le corresponde una valoración social distinta: una mirada que se desvía abruptamente en una conversación, un apretón de manos demasiado enfático en la presentación de una persona, una carcajada estrepitosa en una reunión formal de trabajo, la toma de distancia corporal en el asiento del transporte público, etc. 
determinada cultura y a la conformación de relaciones jerárquicas que constituyen las relaciones éticas de la vida social,. En definitiva, el acto de conocer, entendido convencionalmente como la capacidad de captar las características de algo y otorgarle una descripción identificatoria específica, es un caso derivado de reconocimiento que ya no preserva esas condiciones normativas o, mejor dicho, las ha olvidado (Honneth, 2011, p. 180).

Pues, para Honneth la reificación es un olvido de las condiciones normativas que permite instrumentalizar las relaciones humanas y cosificar las conciencias. Este aspecto lo desarrolla en un estudio sobre Historia y conciencia de clases de Lukács, que a la vez retoma el célebre aforismo adorniano "toda reificación es un olvido" extraído de la Dialéctica de la Ilustración. En el fondo, se podría colegir que el acto mismo de conocer, despojado de todo contenido ético, es cifrado como una cosificación deshumanizadora (Honneth, 2007).

En suma, a partir de las reflexiones acerca de la invisibilización como supresión del reconocimiento, Honneth intenta problematizar el esquema básico que representaría el acto de cognición como una relación aséptica de un sujeto frente a un objeto, en orden a sus condiciones sociales y normativas. En ese marco, sugiere elaborar una epistemología moral que resignifique la propia noción de conocimiento y también, podríamos añadir nosotros, de ignorancia.

\section{Palabras finales a modo de conclusión: abordajes en tensión en torno a la ignorancia y el conocimiento}

El presente recorrido permite considerar, en primer lugar, la relevancia de la ignorancia como tópico epistemológico. La perspectiva de Karl Popper resulta muy fructífera para trastocar cierta concepción arraigada de la ignorancia que la identifica como la mera contraparte negativa del conocimiento. El consagrado defensor del falsacionismo nos muestra que la ignorancia debe entenderse como un principio activo en la producción de conocimiento y en el progreso de la ciencia.

Asimismo, la referencia a Charles W. Mills nos transporta hacia otro encuadre analítico. Su epistemología de la ignorancia nos advierte hasta qué punto la ignorancia se encuentra enraizada en la reproducción de la vida social y en el ejercicio del poder; no puede ser tomada exclusivamente en su valor epistémico. 
En el marco de la teoría del reconocimiento de Honneth, que aquí se plantea en continuidad con la propuesta de Mills, hemos hecho referencia a la invisibilidad social y sus implicaciones epistemológicas y éticas. Bajo esos términos, se desprenden algunas apreciaciones relevantes acerca del conocimiento y la percepción. En ese sentido, el propio acto cognitivo aparece como un fenómeno de segundo orden: una derivación y una cristalización de un acontecimiento normativo-social más fundamental. Si proseguimos el razonamiento expuesto por nuestro autor en torno al conocimiento, esa relación entre sujeto cognoscente y objeto de estudio abstraído del trasfondo recognoscitivo no representa nada más que la consumación de la cosificación y la instrumentalización de los vínculos humanos. La correlación entre sujeto y objeto supondrá la captación del otro objetivado y la disposición a ser utilizado como medio, extrañado de sus condiciones normativas. La epistemología moral que propone Honneth se encargaría de reconstruir tales condicionamientos olvidados.

Sin embargo, a nuestro juicio, permanece la siguiente inquietud: en qué medida, el abordaje moral y social no acaba fagocitando la reflexión filosófica acerca del conocimiento y disolviéndola en cuestiones sociológicas o éticas. Por cierto, la reconstrucción de las condiciones sociales y normativas del acto cognitivo no reemplaza la pregunta eminentemente filosófica acerca de ¿qué es el conocimiento’, ¿cuál es su naturaleza?, ¿qué requisitos debe reunir algo para calificar como tal ${ }^{11}$ ? ¿Hallamos en Mills y en Honneth una teoría del conocimiento o una filosofía de la ciencia que pueda responder a estas interrogaciones? Si omitimos este tipo de tratamiento analítico-conceptual, se corre el riesgo de dar por sentado una noción de conocimiento que debería problematizarse. El énfasis en que Popper rechaza una sociologización del conocimiento se debe en parte a la convicción de que esa postura solo intenta desviar el problema del conocimiento hacia una cuestión social y política al esgrimir la disputa por el poder y las intenciones subjetivas como explicaciones últimas de los eventos cognoscitivos - como en las diferentes versiones de teorías conspirativas-. Deja así intacto un optimismo epistemológico ingenuo y una cuestionable versión de la verdad manifiesta.

Desde luego, no queremos afirmar con eso que, en definitiva, Popper atesora la completa razón en esta encrucijada y, por lo tanto, conviene separar cuidadosamente los

11 Recojo aqui el tipo de interrogantes que postula, por ejemplo, el pensador mexicano Luis Villoro (1989), al señalar la importancia de delimitar el análisis estrictamente filosófico acerca del conocimiento de cualquier investigación científica, ya sea sociológica, psicológica o biológica, ocupada más bien por el conocimiento en cuanto fenómeno empírico (pp. 11-12). 
aspectos sociales e históricos de lo estrictamente filosófico. Tanto Honneth como Mills ofrecen contribuciones imprescindibles si queremos evitar caer en una concepción del conocimiento y la ignorancia excesivamente restringida e idealista, que desvincule los componentes extra-epistémicos.

Acaso sería un grave error plantear este asunto en términos de una implacable disyuntiva entre dos perspectivas que, en última instancias, no son necesariamente excluyentes entre sí. Tal vez convendría permanecer en esa tensión entre distintos tipos de abordajes para un área temática que presenta diversas dimensiones y así obtener una panorámica lo más enriquecedora y menos unilateral posible acerca del conocimiento y de la ignorancia.

\section{Referencias}

Hernández, F. J. y Herzog, B. (2011). Introducción: Axel Honneth: estaciones hacia una teoría crítica recognoscitiva. En A. Honneth, La sociedad del desprecio (pp. 9-38). Madrid: Trotta.

Honneth, A. (1997). La lucha por el reconocimiento. Por una gramática moral de los conflictos sociales. Barcelona: Crítica.

Honneth, A. (2007). Reificación. Un estudio en la teoría del reconocimiento. Buenos Aires: Katz.

Honneth, A. (2009). Crítica del poder. Fases en la reflexión de una Teoría Crítica de la sociedad. Madrid: Antonio Machado libros.

Honneth, A. (2010). Reconocimiento y menosprecio. Sobre la fundamentación normativa de una teoría social. Buenos Aires: Katz.

Honneth, A. (2011). Invisibilidad. Sobre la epistemología moral del reconocimiento. En La Sociedad del desprecio (pp. 165-181). Madrid: Trotta.

Honneth, A. (2014). El derecho de la libertad. Esbozo de una eticidad democráctica. Buenos Aires: Katz.

Klimovsky, G. (1997). Las desventuras del conocimiento científico. Una introducción a la epistemología. Buenos Aires: A-Z Editores. 
Mills, Charles W. (1997). The Racial Contract. Nueva York: Cornell University Press.

Mills, Charles W. (2007). White ignorance. En S. Shannon y N. Tuana (eds.), Race and Epistemologies of Ignorance (pp. 13-38). Albany: State University of New York Press.

Olivé, L. (2000). El bien, el mal y la razón. Facetas de la ciencia y de la tecnología. México: Paidós.

Popper, K. (1973). La lógica de las ciencias sociales. En T. W. Adorno, La disputa del positivismo en la sociología alemana (pp. 101-119). Barcelona: Grijaldo.

Popper, K. (1980). La lógica de la investigación científica. Tecnos: Madrid.

Popper, K. (1985). Prefacio de 1956. Sobre la inexistencia del método científico. En Realismo y el objetivo de la ciencia (pp. 45-48). Madrid: Tecnos.

Popper, K. (1992). Introducción. Sobre las fuentes del conocimiento y la ignorancia. En Karl Conjeturas y refutaciones. El desarrollo del conocimiento científico (pp. 23-54). Paidós: Barcelona.

Popper, K. (2001). El conocimiento de la ignorancia. Polis. Revista Latinoamericana, 1, 1-5. Recuperado de: http://journals.openedition.org/polis/8267

Popper, K. (2006). La filosofía oracular y la rebelión contra la razón. En La sociedad abierta y sus enemigos (pp. 437-470). Barcelona: Paidós.

Shannon, S. y Tuana, N. (2007). Introduction. En S. Shannon y N. Tuana (eds.), Race and Epistemologies of Ignorance (pp. 1-10). Albany: State University of New York Press.

Thuillier, P. (1975). La manipulación de la ciencia. Madrid: Fundamentos.

Villoro, L. (1989). Creer, saber, conocer. México: Siglo XXI. 